\title{
LOW-THRESHOLD HEAT RECEPTOR IN CHICK SENSORY NEURONS IS UPREGULATED INDEPENDENTLY OF NERVE GROWTH FACTOR AFTER NERVE INJURY
}

\author{
J. WACH, ${ }^{a 1}$ A. MARÍN-BURGIN, ${ }^{a 1}$ A. KLUSCH, ${ }^{a}$ \\ C. FORSTER, ${ }^{b}$ S. ENGERT, ${ }^{a}$ A. SCHWAB $^{a}$ AND \\ M. PETERSEN ${ }^{\text {** }}$ \\ aInstitute of Physiology, University of Würzburg, Röntgenring 9, 97070 \\ Würzburg, Germany \\ ${ }^{b}$ Institute of Physiology and Experimental Pathophysiology, University \\ of Erlangen-Nürnberg, Universitätsstrasse 17, 91054 Erlangen, Ger- \\ many
}

\begin{abstract}
In mammals, the cloned low-threshold heat receptor, vanilloid receptor subtype 1 (VR1), is involved in the genesis of thermal hyperalgesia after inflammation. However, there is evidence that VR1 is not involved in the thermal hyperalgesia that occurs after nerve injury. In search for other heat receptors which might be involved in this phenomenon, we previously demonstrated that chick dorsal root ganglion neurons, which are insensitive to capsaicin, respond to low-threshold heat. Here, we investigated whether expression of the low-threshold noxious heat receptor in chicks is regulated by nerve growth factor (NGF), as VR1 is in mammals. Heat $\left(44^{\circ} \mathrm{C}\right)$ responsiveness of isolated dorsal root ganglion neurons of chicks was investigated (i) under culture conditions for up to 4 days with and without NGF and (ii) after a tight ligation of the sciatic nerve for up to 6 days, using cobalt-uptake method. In every case, a significant upregulation in the proportion of heat-responsive neurons was observed. On the molecular level, there was an increase of chick VR1 mRNA level in dorsal root ganglion cells cultured for 3 days in medium lacking NGF. In rat dorsal root ganglion neurons cultured for 1-4 days without NGF, patch-clamp experiments revealed that after 1 day almost all neurons responding to heat also responded to capsaicin, whereas after 3-4 days, more than one-half of the heat-responsive neurons did not respond to capsaicin.

These data suggest the existence of low-threshold heat receptors in chick dorsal root ganglion neurons, the expression of which is regulated independently of NGF. (C) 2003 IBRO. Published by Elsevier Science Ltd. All rights reserved.
\end{abstract}

Key words: axotomy, dorsal root ganglion, VR1, thermal hyperalgesia.

The sensation of pain is caused by the stimulation of primary afferent neurons called nociceptors. These neu-

\footnotetext{
${ }^{1}$ These authors contributed equally to this work.

*Corresponding author. Tel: +49-931-31-2728; fax: +49-931-312741.

E-mail address: marlen.petersen@mail.uni-wuerzburg.de (M. Petersen).

Abbreviations: D-MEM, Dulbecco's modified Eagle's medium; DRG, dorsal root ganglion; HEPES, $\mathrm{HCO}(3-)$-free $\mathrm{N}$-2-hydroxyethylpiperazine- $N$ '-2-ethanesulfonic acid; NGF, nerve growth factor; SNS, tetrodotoxin-resistant sensory-neuron-specific sodium channel; VR1, va-
} nilloid receptor subtype 1; VRL1, vanilloid receptor-like protein 1. rons respond to mechanical, chemical and thermal stimuli at noxious intensities. Regarding heat, considerable progress has been made in understanding the mechanism of activation of nociceptors on the molecular level. Two heat-transducing molecules have been cloned from dorsal root ganglion (DRG) neurons of mammals, named vanilloid receptor 1 (VR1) (Caterina et al., 1997) and the homologous vanilloid receptor-like protein 1 (VRL1) (Caterina et al., 1999). VR1 responds to low-threshold heat (approximately $43^{\circ} \mathrm{C}$ ) stimuli, and also to vanilloid compounds like capsaicin, as shown by heterologous expression in transfected mammalian cells or frog oocytes (Caterina et al., 1997). VRL1 responds to high-threshold heat (approximately $52{ }^{\circ} \mathrm{C}$ ) but is insensitive to capsaicin (Caterina et al., 1999).

It is well established that the expression of VR1 in DRG neurons requires nerve growth factor (NGF). For example, interruption of the retrograde transport of NGF from the periphery to the soma by nerve injury (Johnson et al., 1987) downregulates VR1 (Michael and Priestley, 1999). In addition, the capsaicin-sensitivity of DRG neurons decreases in culture lacking NGF (Winter et al., 1988; Bevan and Winter, 1995). In contrast, in electrophysiological experiments in rat and mouse DRG neurons, NGF acutely increases responsiveness to capsaicin and heat (Shu and Mendell, 1999; Stucky and Lewin, 1999a). In mice overexpressing NGF in skin, the number of heat-evoked action potentials per C fiber is increased (Stucky et al., 1999b). Functionally, experiments in mice with a VR1 gene disruption showed that VR1 is required for the development of heat hyperalgesia under inflammatory conditions induced by injection of mustard oil (Caterina et al., 2000), carageenan (Davis et al., 2000) or NGF (Chuang et al., 2001) into the hind paw. However, VR1 is not essential for the development of thermal hypersensitivity after a partial ligation of the sciatic nerve (Caterina et al., 2000). Moreover, VR1 knock-out mice show an acute response to noxious heat (Caterina et al., 2000; Davis et al., 2000). Therefore, it is likely that another receptor distinct from VR1 but also transducing low-threshold heat is expressed.

Recently, we showed that application of low-threshold heat (approximately $43^{\circ} \mathrm{C}$ ) stimuli elicited inward currents in isolated chick DRG neurons whereas capsaicin had no effect (Marín-Burgin et al., 2000). This finding suggested the expression of a low-threshold heat-transducing receptor distinct from VR1. Indeed, a capsaicin-insensitive avian receptor ortholog named cVR1 has recently been cloned (Jordt and Julius, 2002).

0306-4522/03\$30.00+0.00 (c) 2003 IBRO. Published by Elsevier Science Ltd. All rights reserved. doi:10.1016/S0306-4522(02)00956-9 
Table 1. Chick vanilloid receptor subtype 1 and chick SNS primers used in the experiments

\begin{tabular}{lllr}
\hline Primer & Sequence & $\begin{array}{l}\text { Annealing tem- } \\
\text { perature }\left({ }^{\circ} \mathrm{C}\right)\end{array}$ & $\begin{array}{c}\text { Accession } \\
\text { number }\end{array}$ \\
\hline cVR1-1sense & 5'-GGACCTGGATGATCTGCTG-3' $^{\prime}$ & 57 & AY072909 \\
cVR1-2sense & 5'-CCAGACTGCACTCCACATTG-3' $^{\prime}$ & 57 & $36-57$ \\
cVR1-1rev & 5'-CATCTGCTCCATTCTGGACC-3' & 57 & $180-201$ \\
cSNS-1sense & 5'-AGGACTCAAGATCATTGTAGG-3' & 55 & $571-551$ \\
cSNS-2sense & 5'-AATCTGAGATACAAGTGCGTG-3' & 55 & $109-129$ \\
cSNS-1rev & 5'-TGATATAGACGTTCCCAGTAG-3' & 55 & $230-250$ \\
\hline
\end{tabular}

Some features of the low-threshold heat receptor in chick have been described (Marín-Burgin et al., 2000; Klusch et al., 2002). However, the mechanism regulating its expression is not known. In the present study we asked whether the expression of the receptor in chick is regulated by NGF as VR1 is in rats.

We determined the proportion of isolated chick DRG neurons responding to low-threshold heat (i) with time in culture with and without NGF, in comparison to rat neurons, and (ii) after a tight ligation of the sciatic nerve. On the molecular level, we investigated the chick VR1 mRNA level in DRG cells cultured for 1 day and 3 days without NGF. In addition, we investigated whether rat neurons cultured in medium lacking NGF respond to low-threshold heat but not to capsaicin. Part of the data have been published previously in abstract form (Marín-Burgin et al., 2001).

\section{EXPERIMENTAL PROCEDURES}

\section{Animals}

DRG neurons from chick (100-140 g for the cobalt uptake, patchclamp experiments, and PCR experiments; $100-500 \mathrm{~g}$ for nerve ligation experiments) and male Sprague-Dawley rat (180-250 g for cobalt uptake experiments; 35-70 g for patch-clamp experiments) were used. The experimental protocol was approved by the local animal care committee. Care was taken to minimize the number of animals used and their suffering.

\section{Cell dissociation and culture}

The DRG neurons were isolated enzymatically and mechanically as described previously (Petersen et al., 1996). Animals were killed with an i.p. lethal dose of sodium pentobarbital and DRGs from all segments of the spinal cord were excised. The ganglia were incubated in Dulbecco's modified Eagle's medium (D-MEM) (Gibco, Eggenstein, Germany) containing collagenase type CLS IV (260 U/mg) (Biochrom, Berlin, Germany) at $37^{\circ} \mathrm{C}$ for $90-135$ min (depending on the weight of the animals) followed by an incubation for $11 \mathrm{~min}$ in D-MEM containing trypsin (9820 U/ml) (Sigma, Neu-Ulm, Germany). The ganglia were suspended in D-MEM containing gentamicin $(25 \mu \mathrm{g} / \mathrm{ml})$ (Gibco) and mechanically dissociated. Cells were centrifuged and suspended in Ham's F12 medium supplemented with $10 \%$ heat-inactivated horse serum (Gibco), 2-mM L-glutamine (Biochrom), $100 \mathrm{U} / \mathrm{ml}$ penicillin (Gibco), $100 \mu \mathrm{g} / \mathrm{ml}$ streptomycin (Gibco) and $100 \mathrm{ng} / \mathrm{ml}$ NGF 7S (Calbiochem-Novabiochem, Bad Soden, Germany), isolated from mouse submaxillary glands, as indicated. In some experiments serum-free TNB 100 medium was used, supplemented with TNB 100 lipid protein complex (Gibco), $100 \mathrm{U} / \mathrm{ml}$ penicillin, $100 \mu \mathrm{g} / \mathrm{ml}$

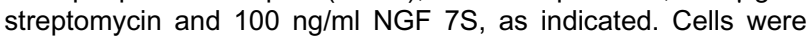
plated on sterile $10-\mathrm{mm}$ glass coverslips coated with $200 \mu \mathrm{g} / \mathrm{ml}$
poly-L-lysine (Sigma) and maintained in supplemented F12 or TNB 100 medium. Neurons were kept in culture for 1-6 days, as indicated, at $37{ }^{\circ} \mathrm{C}$ and $3.5 \% \mathrm{CO}_{2}$. Half of the medium was replaced daily. The protocol for cell dissociation and culture was the same for both species.

\section{Nerve injury}

Chicks were anesthetized with sodium pentobarbital $(30 \mathrm{mg} / \mathrm{kg})$ and the right sciatic nerve was exposed at midthigh level. Three silk threads were tightly tied around it proximal to the trifurcation. After 2, 4 or 6 days, animals were killed by an overdose of pentobarbital. In chicks, the sciatic nerve projects to sacral DRG S4 to S9 (King and McLelland, 1985); therefore, ipsilateral ganglia S4 to S8/9 were taken. The same DRG from uninjured animals were taken as controls. Neurons were isolated as described above and kept in culture for 1 day.

\section{Cobalt uptake experiments}

To determine the proportion of neurons responsive to heat stimuli or to capsaicin (i) in normal neurons in culture medium with or without NGF or (ii) in neurons after ligation of the sciatic nerve, the cobalt uptake method was performed (Hogan, 1983; Winter, 1987; Reichling et al., 1997). Briefly, neurons were washed for $2 \mathrm{~min}$ in assay buffer $\left(37^{\circ} \mathrm{C}\right.$ ) containing (in $\mathrm{mM}$ ): $5.8 \mathrm{NaCl}, 5 \mathrm{KCl}, 2 \mathrm{MgCl}_{2}$, $0.75 \mathrm{CaCl}_{2}, 12$ glucose, 10 HEPES; osmolarity was adjusted to $290 \mathrm{mOsm}, \mathrm{pH}$ 7.4. For stimulation of rat neurons with capsaicin, coverslips were incubated in assay buffer containing $5-\mathrm{mM} \mathrm{CoCl}_{2}$ $\left(\mathrm{Co}^{2+}\right.$-assay buffer) and 300-nM capsaicin for $8 \mathrm{~min}$ at room temperature. For thermal stimulation, neurons from rat or chick, respectively, were placed into $\mathrm{Co}^{2+}$-assay buffer preheated to the stimulus temperature of $44{ }^{\circ} \mathrm{C}$ and kept in a temperature-controlled chamber for $8 \mathrm{~min}$. The cells were then washed for $2 \mathrm{~min}$ in assay buffer at room temperature and placed into $1 \%$ ammonium sulfide (diluted in assay buffer, 298 mOsm) (Fluka, Neu-Ulm, Germany) for 2 min to precipitate the cobalt to cobalt sulfide. In order to detect dead cells, coverslips were incubated in $0.1 \%$ Trypan Blue (Fluka) for $10 \mathrm{~min}$. Cells were washed, fixed in $4 \%$ paraformaldehyde and mounted in DABCO (Sigma). To rule out heat-activated cobalt influx via voltage-dependent calcium channels, control experiments were performed in chick neurons in the presence of $100-\mu \mathrm{M}$ lanthanum (Reichling and MacDermott, 1991). To determine possible background cobalt staining, control experiments were performed in chick neurons at ambient temperature $\left(23-27^{\circ} \mathrm{C}\right)$ after $1-4$ days under culture conditions in $\mathrm{F} 12$ medium with and without NGF.

\section{PCR experiments}

Total RNA was isolated with RNeasy spin columns (Qiagen, Hilden, Germany) from chick DRG cells after 1 or 3 days of cell culture without NGF, respectively. RNA $(1.5 \mu \mathrm{g})$ was used for cDNA synthesis with Superscript II reverse transcriptase (Gibco) using oligo(dT) $)_{18}$ primers. Table 1 lists the homologous primers used for amplifying fragments from chick VR1 and chick tetrodo- 

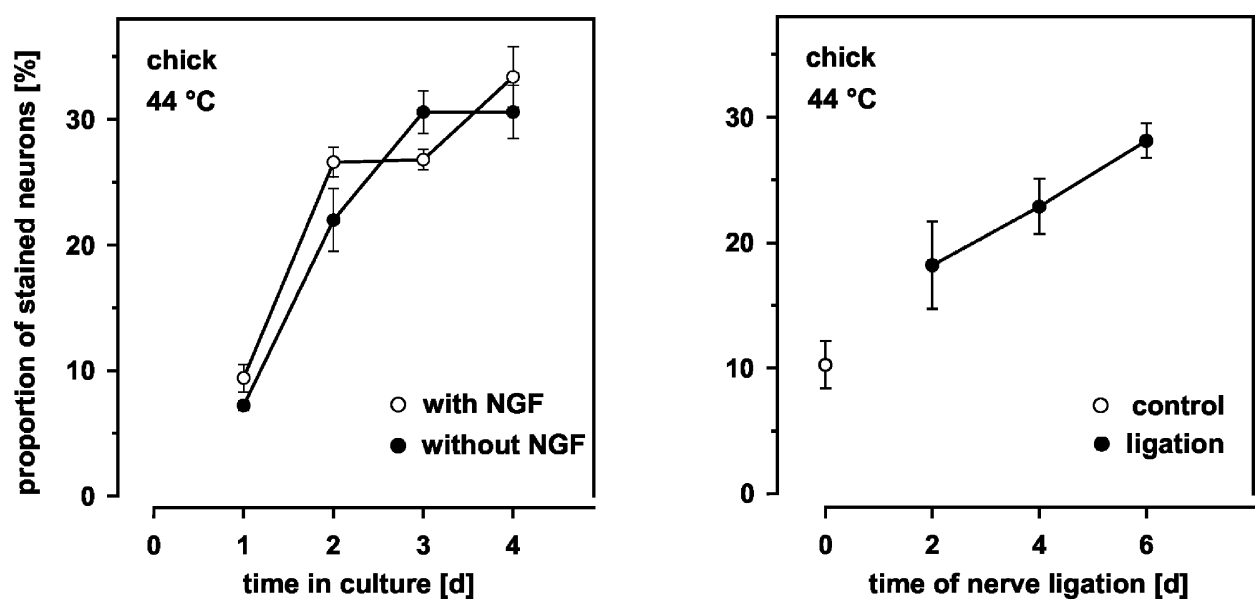

Fig. 1. Proportion of chick dorsal root ganglion (DRG) neurons with cobalt staining induced by heat $\left(44^{\circ} \mathrm{C}\right)$. Left: With time in culture. Open circles, in medium with nerve growth factor (NGF); filled circles, without NGF. Right: After nerve injury, followed by 1 day in culture without NGF. Open circle at $0 \mathrm{~d}$ indicates control from S4 to $\mathrm{S} 8 / 9$ neurons from uninjured animals; filled circles, injured ipsilateral side. Values are expressed as mean $\pm \mathrm{SEM}$; $n=$ five to eight animals; total of $500-800$ neurons per data point.

toxin-resistant sensory-neuron-specific sodium channel (SNS) with a Progene thermocycler. They were derived from chick VR1 (Jordt and Julius, 2002; accession number AY072909) and a partial chick SNS sequence (Friedel et al., 1997; accession number AJ 001491). The specificity of the amplicons was tested by means of nested PCR. Chick VR1 mRNA levels were determined by semiquantitative PCR analysis. Ten-microliter aliquots of a $120-\mu$ I PCR reaction mix were taken after 22, 25, 28, 31, and 34 cycles of amplification. Amplified cDNA fragments were size-fractionated in a $6 \%$ polyacrylamide gel and stained with ethidium bromide. The optical density of the bands was measured with ImageJ software.

\section{Whole-cell patch-clamp experiments}

Experiments were performed as described previously (Petersen et al., 1996). Briefly, coverslips were continuously superfused with external solution $(0.5 \mathrm{ml} / \mathrm{min})$. Neurons were voltage-clamped at $-80 \mathrm{mV}$ using an Axopatch 200A amplifier (Axon Instruments). Series resistance and cell capacitance were compensated by the amplifier circuitry. The clamp command signals were generated via the amplifier and a PC with a DigiData 1200 interface and pClamp 6.0 software (Axon Instruments, Union City, CA, USA). Electrodes had a resistance between 2 and $6 \mathrm{M} \Omega$. They were filled with (mM): $140 \mathrm{KCl}, 1 \mathrm{CaCl}_{2}, 11 \mathrm{EGTA}, 10$ HEPES, $2 \mathrm{Mg}$-ATP; $\mathrm{pH}$ 7.3. The external solution consisted of $(\mathrm{mM}): 140 \mathrm{NaCl}, 3.5 \mathrm{KCl}, 2$ $\mathrm{CaCl}_{2}, 1 \mathrm{MgCl}_{2}, 10$ HEPES; $\mathrm{pH}$ 7.3.

Test solutions were applied via a fast multichannel superfusion system (Dittert et al., 1998). The orifice was placed at a distance of less than $100 \mu \mathrm{m}$ from the neuron. Solutions were changed by a microprocessor controlling the activation of valves. Temperature stimuli were recorded together with the evoked inward current using Clampex 6.0 software. Ramp-shaped heat stimuli starting from ambient temperature were used with 2-s maximum temperature duration. The response to $1-\mu \mathrm{M}$ (rat) or $10-\mu \mathrm{M}$ (chick) capsaicin was tested by superfusion for $20-50 \mathrm{~s}$ before or after the heat stimuli. Only one neuron on each coverslip was tested. Small- to medium-sized neurons were selected.

\section{Data analysis of the cobalt-uptake experiments}

For cobalt-uptake experiments neurons were analyzed with a Zeiss microscope (Axiophot) coupled to a CCD color video camera (Sony) and an OPTIMAS image analyzing system (Optimas Corporation, Seattle, WA).
Four to eight animals were used for each experiment. For each data point, one coverslip per animal was used and 100 neurons per coverslip were analyzed. Neurons were selected by systematic scanning of the coverslip. All cobalt-stained and unstained neurons unobstructed by other neurons or by tissue debris and not stained blue by the Trypan Blue were included in the data set. The criterion for a responsive neuron was a distinct brown color caused by the cobalt sulfide precipitate. This was determined by visual inspection. The data analysis was performed with the investigator blinded to the identity of the coverslips.

\section{Statistics}

If not stated otherwise, statistical tests were performed using ANOVA repeated measure designs. Planned comparisons were used to test for differences between selected values. All calculations were done using the STATISTICA software package (Statsoft Inc.). The results of the ANOVA include the test statistics ( $F$ value) and the $P$ values of the effect. A probability of $P<0.05$ was regarded as significant. Values are given as mean \pm S.E.M.

\section{Solutions}

Capsaicin solution was prepared from a stock solution of 5.45-mM ethanol, stored at $-20^{\circ} \mathrm{C}$. Lanthanum stock solution $(1.0 \mathrm{mM})$ was diluted in assay buffer adjusted to $\mathrm{pH} 7.4$.

\section{RESULTS}

\section{Experiments in chick neurons}

To investigate whether the proportion of chick neurons responding to low-threshold heat depends on NGF, experiments were performed on dissociated neurons cultured for 1-4 days with and without NGF in F12 medium. Neurons responding to heat were functionally identified by the cobalt-uptake method, in which the stimulus-evoked cobalt uptake is visualized by precipitating the cobalt with sulfide to yield a brown staining of the neurons.

We found a significant increase in the proportion of neurons responding to heat $\left(44^{\circ} \mathrm{C}\right)$ with time in culture (ANOVA, $F=74.3$ ) (Fig. 1, left). This increase was independent of NGF $(F=2.6, P>0.17)$. After 1 day in culture 

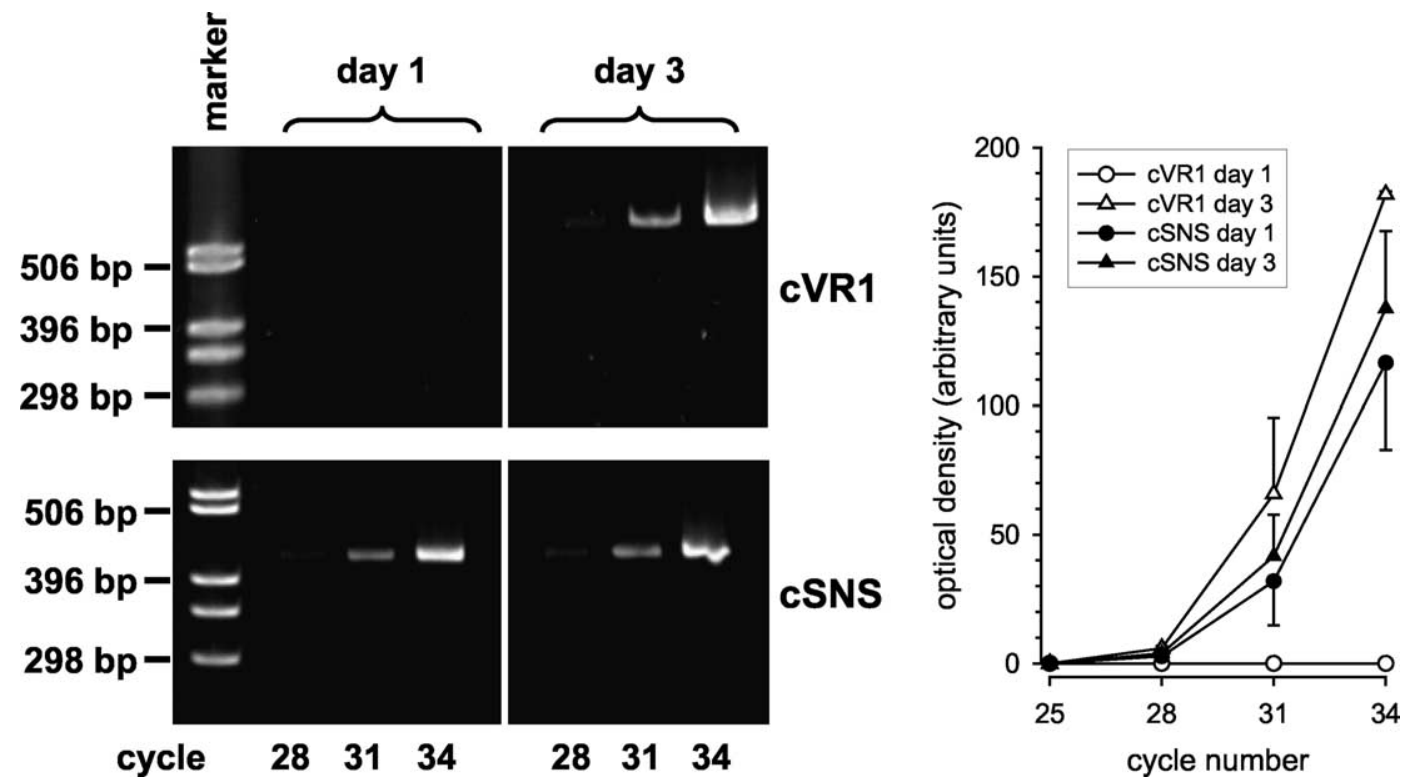

Fig. 2. Semiquantitative PCR analysis of chick vanilloid receptor subtype 1 (VR1) mRNA and SNS mRNA levels. Left: PAGE gels of amplified cDNA fragments of the chick heat receptor cVR1 (619 bp; top) and of the chick voltage-dependent Na ${ }^{+}$channel cSNS (422 bp; bottom). Right: Summary of semiquantitative PCR analysis of chick VR1 and SNS mRNA levels. Experiments were performed in dorsal root ganglion (DRG) cells after 1 day and 3 days in culture lacking nerve growth factor (NGF). Values are expressed as mean \pm SEM; $n=$ three animals.

with NGF in the medium ( $n=$ five animals), $9.4 \pm 1.1 \%$ of the neurons responded to heat, without NGF ( $n=$ five animals), the proportion was $7.2 \pm 0.4 \%$. After 2 days in culture, the proportion had increased to $26.6 \pm 1.2 \%$ in medium with NGF and to $22.0 \pm 2.5 \%$ without NGF. Cobalt-stained neurons were small to medium in size, regardless of time in culture and the presence or absence of NGF in the medium. The mean cross-sectional area of neurons after 1 day with NGF was $533 \pm 42 \mu \mathrm{m}^{2}(n=47)$; after 4 days it was $504 \pm 18 \mu \mathrm{m}^{2} \quad(n=164)$. Without NGF the values were $529 \pm 43 \mu \mathrm{m}^{2}(n=36)$ and $519 \pm 18 \mu \mathrm{m}^{2}(n=153)$, respectively.

To exclude the possibility that the increase in the proportion of heat-responsive neurons was caused by factors in the serum added to the F12 medium, corresponding experiments were performed on neurons cultured in serum-free TNB 100 medium ( $n=$ three to four animals). Under these conditions, there was also an NGF-independent increase in the proportion of neurons responding to heat. After 1 day in culture with NGF, $1.8 \pm 0.3 \%$ of neurons responded to heat; in culture without NGF, $1.6 \pm 0.5 \%$. After 4 days, the proportion was $25.5 \pm 4.5 \%$ in culture with NGF and $22.5 \pm 2.9 \%$ without NGF. Thus, the proportion of heat-responsive neurons increased with time in culture, and this increase was independent of the presence or absence of NGF or serum in the medium. However, compared with the proportions of responsive neurons in F12 medium with serum, in serum-free TNB medium there was a shift to lower proportions.

To detect possible unspecific background staining, control experiments were performed at ambient temperature $\left(23-27^{\circ} \mathrm{C}\right)$. Neurons were kept in culture for 1, 2, 3 and 4 days in medium with or without NGF ( $n=$ three animals, 300 neurons for each data point). In medium with
NGF, the percentage of stained neurons was $1.3 \%, 1.3 \%$, $0.7 \%$ and $0.0 \%$, respectively. In medium without NGF, the values were $2.0 \%, 1.0 \%, 1.7 \%$, and $0.7 \%$, respectively.

Next, we asked whether the upregulation of the proportion of heat-responsive neurons observed with time in culture without NGF is also present after pre-injury in vivo. A tight ligation of the sciatic nerve for 2-6 days was performed to interrupt retrograde NGF transport from the periphery to the soma. Then, the respective DRG neurons S4 to S8/9 were isolated followed by a 1-day culture in F12 medium without NGF. As shown in Fig. 1 right, the proportion of heat-responsive neurons increased with time of ligation; this increase was significant for days 2-6 (Wilcoxon matched pair, $P<0.03)$. In control animals without ligation ( $n=$ eight animals), the percentage of neurons from ganglia $S 4$ to $S 8 / 9$ responding to $44{ }^{\circ} \mathrm{C}$ was $10.3 \pm 1.9 \%$. In the group of animals with ligation $(n=5)$, the proportion of heat-responsive neurons was significantly higher. After 2 days, $18.2 \pm 3.5 \%$ of neurons responded to heat (Student's $t$-test: $P<0.001$ compared with control) and after 6 days this proportion increased further to $28.1 \pm 1.4 \%$ of neurons $(P<0.0002)$.

Thus, both under in vitro and in vivo conditions there was an upregulation of the proportion of heat-responsive neurons.

We then asked whether the increase in the proportion of heat-responsive neurons is accompanied by an increased transcription of the chick VR1. Therefore, a semiquantitative PCR analysis of chick VR1 mRNA levels was performed in DRG cells cultered without NGF. Fig. 2 shows that no chick VR1 cDNA fragment could be amplified from cells after 1 day in culture. In contrast, chick VR1 was readily detectable after 3 days. This increase of chick VR1 mRNA level is not due to a general increase in tran- 

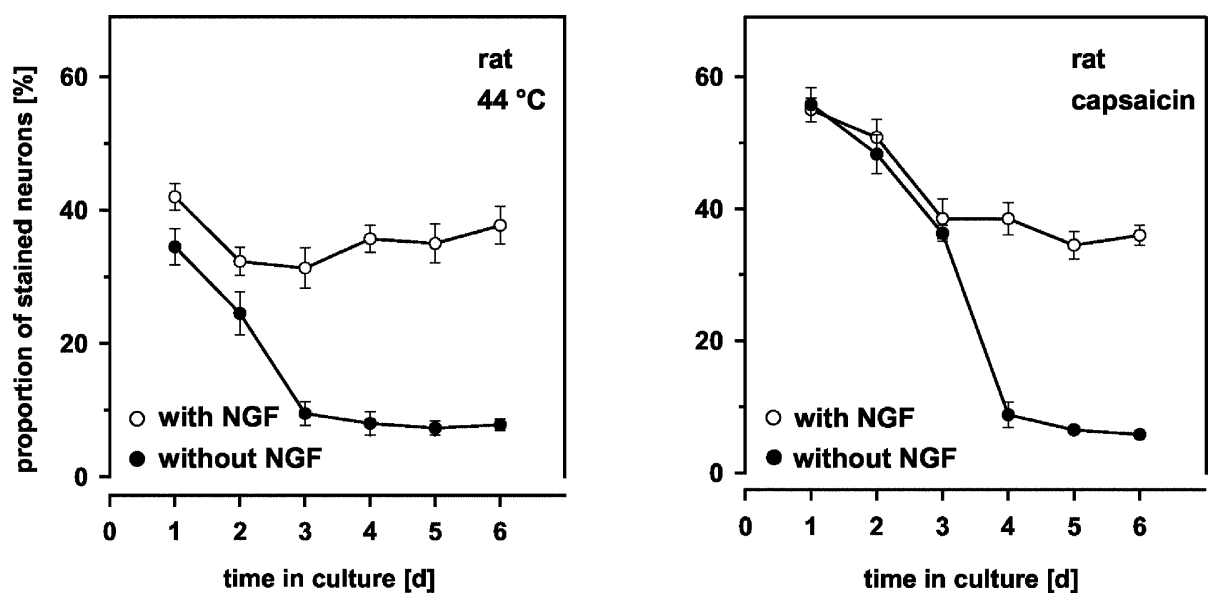

Fig. 3. Proportion of rat dorsal root ganglion (DRG) neurons with cobalt staining induced by $44^{\circ} \mathrm{C}$ (left) or 300 -nM capsaicin (right) with time in culture. Open circles, in medium with nerve growth factor (NGF); filled circles, without NGF. Values are expressed as mean \pm SEM; $n=$ four to six animals; total of 400-600 neurons per data point.

scription, since mRNA levels of the SNS did not differ between day 1 and day 3 .

\section{Experiments in rat neurons}

We further asked whether the proportion of rat neurons responsive to heat $\left(44{ }^{\circ} \mathrm{C}\right)$ also increased with time in culture. Cobalt-uptake experiments were performed after 1-6 days under culture conditions with and without NGF (Fig. 3 left). Without NGF ( $n=$ four animals), the proportion significantly decreased with time in culture from $34.5 \pm 2.7 \%$ after 1 day to $9.5 \pm 1.8 \%$ after 3 days, remaining at this level until day $6(7.8 \pm 0.8 \%$ ) (day 3 versus day 6 : $P>0.69$ ). Under conditions with NGF ( $n=$ six animals), a small but significant decrease was observed between days $1(42.0 \pm 2.0 \%)$ and $3(31.3 \pm 3.0 \%$; planned comparison: $P<0.014)$, but there was no significant difference between day 1 and day $6(37.7 \pm 2.8 \% ; P>0.219)$. The decrease in the proportion of heat-responsive neurons in medium lacking NGF was expected because in mammals heat is transduced via the NGF-dependent receptor VR1. However, upregulation of other low-threshold heat receptors cannot be excluded (Caterina et al., 2000; Davis et al., 2000).

For capsaicin, which can serve as a marker for functional VR1 expression, the response in rat DRG neurons is downregulated under conditions without NGF. A difference in time courses of downregulation between heat- and capsaicin-responsive neurons might be an indication for different heat receptors. In our experiments (Fig. 3 right), without NGF ( $n=$ four animals) the proportion of capsaicinresponsive neurons was $55.8 \pm 2.6 \%$ after 1 day in culture. The proportion significantly decreased to $8.8 \pm 1.9 \%$ after 4 days (planned comparision: $P<0.001$ ) and stayed at this level up to day $6(5.8 \pm 0.6 ; P>0.53)$. With NGF $(n=\operatorname{six}$ animals), there was a similar significant decrease from $55.0 \pm 1.8 \%$ at day 1 to $38.5 \pm 2.4 \%$ at day $4(P<0.001)$; however, in contrast to the proportion of responsive neurons under conditions without NGF, this level was maintained up to day $6(36.0 \pm 1.5 \% ; P>0.36)$.

The cobalt-uptake method can only monitor one response to a stimulus in a given experiment. Therefore, we used the whole-cell patch-clamp method to investigate whether individual rat neurons responded to heat but not to capsaicin under culture conditions lacking NGF. Rat neurons cultured for 1 day without NGF showed inward currents in response to both heat (from ambient temperature to $50 \pm 1^{\circ} \mathrm{C}$ ) and capsaicin $(1 \mu \mathrm{M})$. Out of 12 neurons tested, 11 responded with inward currents to both stimuli. One neuron responded only to heat. The mean resting potential was $-54.8 \mathrm{mV}$; the mean cross-sectional area was $645 \mu \mathrm{m}^{2}(n=12)$. An example of a neuron responding to both stimuli is shown in Fig. 4A. In contrast, in rat neurons cultured for 3 or 4 days without NGF, out of 23 neurons, only nine neurons responded to both heat and capsaicin. Fourteen neurons responded only to heat. The mean resting potential was $-55.6 \mathrm{mV}$, the mean crosssectional area was $597 \mu \mathrm{m}^{2}(n=23)$. An example of a neuron responding to heat only is shown in Fig. 4B. After washout, a heat response could be evoked again. For comparison, an example of a chick neuron which responds to low-threshold heat with an inward current, but not to capsaicin $(10 \mu \mathrm{M})$ is shown (Fig. $4 \mathrm{C}$ ).

\section{DISCUSSION}

In the current study, we showed that the proportion of isolated chick DRG neurons responsive to heat increased with time in culture. This increase was independent of the presence or absence of NGF, indicating that the expression of the receptor neither depends on NGF nor is suppressed by it. In addition, the level of chick VR1 mRNA increased under culture conditions lacking NGF. Therefore, the augmentation of the proportion of heat responsive neurons is likely due to the increase in the transcription of chick VR1 in these cells as revealed by semiquantitative PCR analysis.

Reduction of the NGF level under in vivo conditions by a tight ligation of the sciatic nerve also resulted in an upregulation of the proportion of low-threshold heat responsive neurons on the affected side. This NGF-independent expression of heat receptors in chick DRG neurons is 

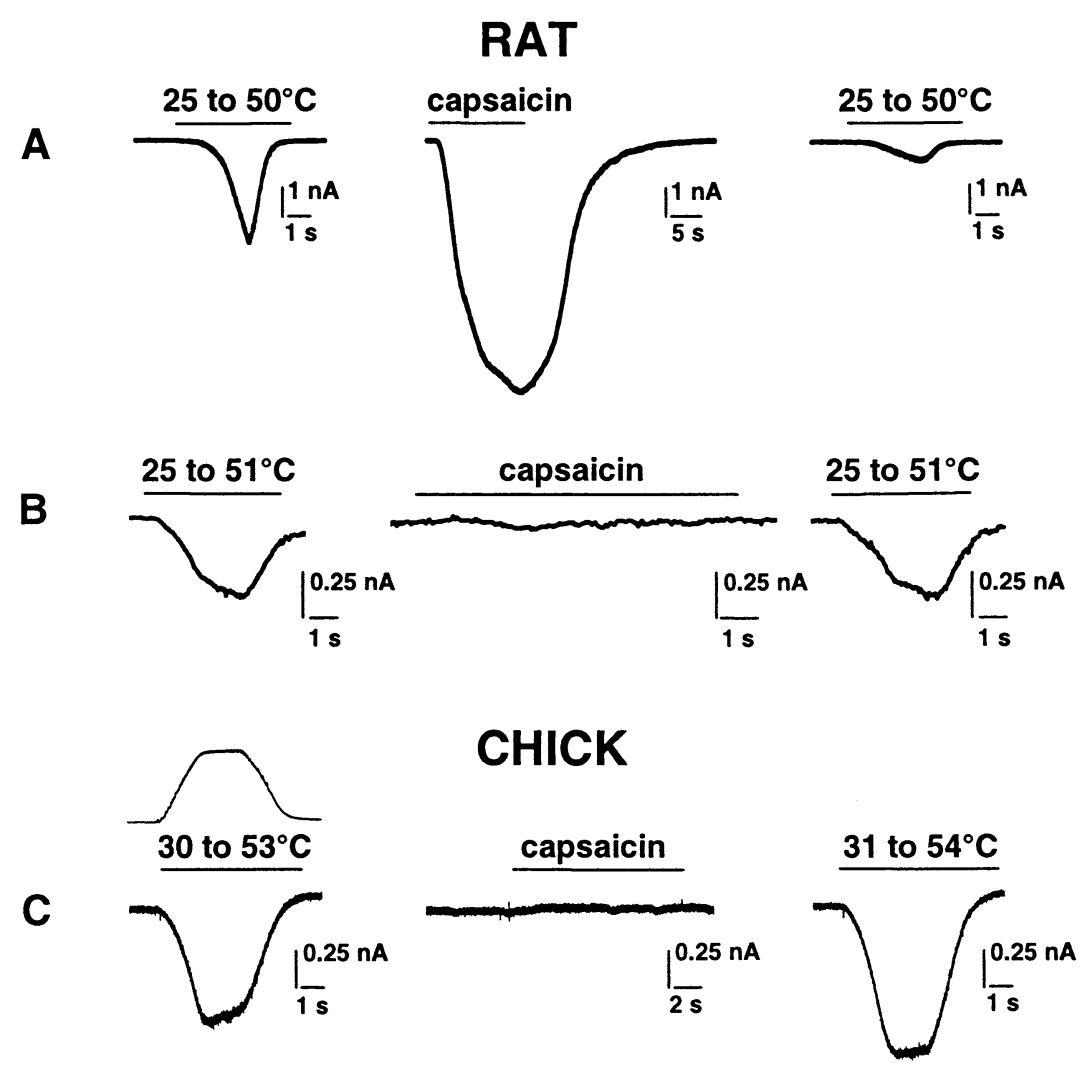

Fig. 4. Whole-cell voltage-clamp recordings of rat (A, B) and chick (C) dorsal root ganglion (DRG) neurons in response to heat (left) and capsaicin (middle) stimuli. After a washout of $3 \mathrm{~min}$, heat stimuli were applied again (right). Temperature of heat stimuli as indicated, capsaicin concentration for rat $1 \mu \mathrm{M}$, for chick $10 \mu \mathrm{M}$. Stimulus durations are indicated by horizontal bars. An example showing the shape of the heat stimulus is given in $\mathrm{C}$, left. Time in culture was 1 day (A), 3 days (B) and 1 day (C). Membrane potentials: $-56,-64,-60 \mathrm{mV}$; soma cross-sectional areas: $662,810,845$ $\mu \mathrm{m}^{2}$.

in contrast to the NGF-dependent expression of VR1 in rat DRG neurons (Michael and Priestley, 1999). In addition to the capsaicin insensitivity of chick sensory neurons (Szolcsanyi et al., 1986; Sann et al., 1987; Wood et al., 1988; Marín-Burgin et al., 2000), the NGF-independent regulation is a further characteristic distinguishing the chick VR1 heat receptor from the VR1 in mammals.

In rats we showed that in the absence of NGF the proportion of heat-responsive neurons was downregulated during the first 3 days in culture, the proportion of capsaicin-sensitive neurons during the first 4 days. Sensitivity to capsaicin and heat is likely lost due to the downregulation of VR1. For heat sensitivity, it is conceivable that at the same time other heat-transducing receptors are present or are newly expressed. The initial difference between the proportions of heat- and capsaicin-sensitive neurons at day 1 could be explained by the fact that the temperature stimulus of $44{ }^{\circ} \mathrm{C}$ was close to the threshold temperature for activation whereas the capsaicin concentration of 300 $\mathrm{nM}$ was close to the maximum effective concentration (Marín-Burgin et al., 2000). This initial difference, however, was not maintained with time in culture. After 3 or 4 days, respectively, heat and capsaicin sensitivity reached a similar residual level which was clearly above background staining. With respect to heat stimulation, we cannot know whether here VR1 is the transducing molecule or whether another, capsaicin-insensitive, heat receptor is involved. Our whole-cell patch-clamp experiments in rat support the hypothesis of capsaicin-insensitive heat receptors in mammals. Co-sensitivity to heat and capsaicin decreased with length of time in culture in the absence of NGF. Compared with neurons at day 1 there was a dramatic decrease in the percentage of neurons responding to both stimuli after days 3 and 4 . The higher proportion of heat-responsive neurons in the patch-clamp experiments compared with the cobalt-uptake experiments can be explained by the deliberately biased selection of small to medium neurons and in addition by the higher stimulus temperature to maximize the number of responsive neurons. It remains to be resolved whether neurons responding only to heat express a receptor that was never capsaicin-sensitive. Alternatively, it could be that the VR1 loses its capsaicin sensitivity while it is still sensitive to heat. Results by Nagy and Rang (1999) support the first possibility. They describe single channels activated only by heat and not by capsaicin in rat DRG neurons.

Our cobalt-uptake experiments showing downregulation of capsaicin sensitivity confirm data from $\mathrm{Ca}^{2+}$ uptake experiments with time in culture in medium lacking NGF (Winter et al., 1988). In addition, it has been shown that after axotomy expression of VR1 mRNA is markedly reduced (Michael and Priestley, 1999). 
The expression of an NGF-independent heat receptor in mammals could explain thermal hyperalgesia under pathophysiological conditions with a reduced NGF level, like after nerve injury (Caterina et al., 2000; Davis et al., 2000; Chuang et al., 2001).

Acknowledgements-The authors are especially indebted to Drs. Cheryl Stucky and William H. Dantzler for critical reading of the manuscript, and to Tanja Martini for expert technical assistance. This work was funded by Deutsche Forschungsgemeinschaft SFB 353-A11.

\section{REFERENCES}

Bevan S, Winter J (1995) Nerve growth factor (NGF) differentially regulates the chemosensitivity of adult rat cultured sensory neurons. J Neurosci 15:4918-4926.

Caterina MJ, Schumacher MA, Tominaga M, Rosen TA, Levine JD, Julius D (1997) The capsaicin receptor: a heat-activated ion channel in the pain pathway. Nature 389:816-824

Caterina MJ, Rosen TA, Tominaga M, Brake AJ, Julius D (1999) A capsaicin-receptor homologue with a high threshold for noxious heat. Nature 398:436-441.

Caterina MJ, Leffler A, Malmberg AB, Martin WJ, Trafton J, PetersenZeitz KR, Koltzenburg M, Basbaum Al, Julius D (2000) Impaired nociception and pain sensation in mice lacking the capsaicin receptor. Science 288:306-313.

Chuang $\mathrm{H}$, Prescott ED, Kong H, Shields S, Jordt SE, Basbaum Al, Chao MV, Julius D (2001) Bradykinin and nerve growth factor release the capsaicin receptor from Ptdlns(4, 5)P2-mediated inhibition. Nature 411:957-962.

Davis JB, Gray J, Gunthorpe MJ, Hatcher JP, Davey PT, Overend P, Harries MH, Latcham J, Clapham C, Atkinson K, Hughes SA, Rance K, Grau E, Harper AJ, Pugh PL, Rogers DC, Bingham S, Randall A, Sheardown SA (2000) Vanilloid receptor-1 is essential for inflammatory thermal hyperalgesia. Nature 405:183-187.

Dittert I, Vlachova V, Knotkova H, Vitaskova Z, Vyklicky L, Kress M, Reeh PW (1998) A technique for fast application of heated solutions of different composition to cultured neurones. J Neurosci Methods 82:195-201.

Friedel RH, Schnürch H, Stubbusch J, Barde Y-A (1997) Identification of genes differentially expressed by nerve growth factor- and neurotrophin-3-dependent sensory neurons. Proc Natl Acad Sci USA 94:12670-12675.

Hogan PG (1983) Expression of markers for pain sensory neurons in cell culture. PhD dissertation, Harvard University, Cambridge, MA, USA.

Johnson EM Jr, Taniuchi M, Clark HB, Springer JE, Koh S, Tayrien MW, Loy R (1987) Demonstration of the retrograde transport of nerve growth factor receptor in the peripheral and central nervous system. J Neurosci 7:923-929.
Jordt S, Julius D (2002) Molecular basis for species-specific sensitivity to "hot" chili peppers. Cell 108:421-430.

King AS, McLelland J (1985) Form and function in birds, Vol. 3. Academic Press Inc: London.

Klusch A, Schmalfuß A, Petersen M (2002) Sensitization of the low threshold heat-gated current in chick sensory neurons by acidification of the extracellular medium. Pflügers Arch Suppl 443:S315.

Marín-Burgin A, Reppenhagen S, Klusch A, Wendland JR, Petersen M (2000) Low-threshold heat response antagonized by capsazepine in chick sensory neurons, which are capsaicin-insensitive. Eur J Neurosci 12:3560-3566.

Marín-Burgin A, Klusch A, Wach J, Engert S, Petersen M (2001) NGF-independent upregulation of low-threshold heat response in capsaicin-insensitive sensory neurons. Soc Neurosci Abstr 31:510. 10.

Michael GJ, Priestley JV (1999) Differential expression of the mRNA for the vanilloid receptor subtype 1 in cells of the adult rat dorsal root and nodose ganglia and its downregulation by axotomy. $J$ Neurosci 19:1844-1854

Nagy I, Rang HP (1999) Similarities and differences between the responses of rat sensory neurons to noxious heat and capsaicin. J Neurosci 19:10647-10655.

Petersen M, LaMotte RH, Klusch A, Kniffki KD (1996) Multiple capsaicin-evoked currents in isolated rat sensory neurons. Neuroscience 75:495-505.

Reichling DB, Barratt L, Levine JD (1997) Heat-induced cobalt entry: an assay for heat transduction in cultured rat dorsal root ganglion neurons. Neuroscience 77:291-294.

Reichling DB, MacDermott AB (1991) Lanthanium actions on excitatory amino acid-gated currents and voltage-gated calcium currents in rat dorsal horn neurons. J Physiol (Lond) 441:199-218.

Sann H, Harti G, Pierau FK, Simon E (1987) Effect of capsaicin upon afferent and efferent mechanisms of nociception and temperature regulation in birds. Can J Physiol Pharmacol 65:1347-1354.

Shu X, Mendell LM (1999) Nerve growth factor acutely sensitizes the response of adult rat sensory neurons to capsaicin. Neurosci Lett 274:159-162.

Stucky CL, Lewin GR (1999a) Isolectin $B_{4}$-positive and negative nociceptors are functionally distinct. J Neurosci 19:6497-6505.

Stucky CL, Koltzenburg M, Schneider M, Engle MG, Albers KM, Davis BM (1999b) Overexpression of nerve growth factor in skin selectively affects the survival and functional properties of nociceptors. J Neurosci 19:8509-8516.

Szolcsanyi J, Sann H, Pierau FK (1986) Nociception in pigeons is not impaired by capsaicin. Pain 27:247-260.

Winter J (1987) Characterization of capsaicin-sensitive neurones in adult rat dorsal root ganglion cultures. Neurosci Lett 80:134-140.

Winter J, Forbes CA, Sternberg J, Lindsay RM (1988) Nerve growth factor (NGF) regulates adult rat cultured dorsal root ganglion neuron responses to the excitotoxin capsaicin. Neuron 1:973-981.

Wood JN, Winter J, James IF, Rang HP, Yeats J, Bevan S (1988) Capsaicin-induced ion fluxes in dorsal root ganglion cells in culture. J Neurosci 8:3208-3220. 